\title{
Risk Factors of the Recurrences of Pancreatic Solid Pseudopapillary Tumors: A Systematic Review and Meta-analysis
}

\author{
Hao Gao ${ }^{1,2,3, *}$, Yong Gao1,2,3,*, Lingdi Yin 1,2,3,*, Guangfu Wang1,2,3, Jishu Wei1,2,3, Kuirong Jiang 1,2,3 and Yi \\ Miao $^{1,2,3 凶}$ \\ 1. Pancreas Center, The First Affiliated Hospital of Nanjing Medical University, Nanjing, 210029, People's Republic of China. \\ 2. Pancreas Institute of Nanjing Medical University, Nanjing, 210029, People's Republic of China. \\ 3. Department of General Surgery, The First Affiliated Hospital of Nanjing Medical University, Nanjing, 210029, People's Republic of China. \\ *These three authors contributed equally to this work. \\ $\square$ Corresponding author: Yi Miao. E-mail: miaoyi@njmu.edu.cn. Address: Pancreas Center, The First Affiliated Hospital of Nanjing Medical University, 300 \\ Guangzhou Rd, Gulou District, Nanjing, 210029, People's Republic of China. \\ (c) Ivyspring International Publisher. This is an open access article distributed under the terms of the Creative Commons Attribution (CC BY-NC) license \\ (https://creativecommons.org/licenses/by-nc/4.0/). See http://ivyspring.com/terms for full terms and conditions.
}

Received: 2017.12.21; Accepted: 2018.03.01; Published: 2018.04.27

\begin{abstract}
Background: Pancreatic solid pseudopapillary tumors (SPTs) are rare neoplasms with low-grade malignancy. The main treatment for them is surgical resection. However, some SPTs relapse after resection. The risk factors associated with the recurrences of resected SPTs remain controversial to date. We performed a systematic review and meta-analysis to identify the risk factors of the recurrences of pancreatic SPTs.

Materials and Methods: We searched PubMed, EMBASE, and the Cochrane Library from their inception to December 2017. Studies that focused on the risk factors of postoperative relapses of pancreatic SPTs were enrolled. Combined ORs with $95 \%$ Cls were calculated to evaluate the effects of relevant factors investigated in eligible studies. Heterogeneity among combined results was assessed by Cochran's $Q$ test and by the degree of inconsistency $\left(I^{2}\right)$. Statistical analyses were performed by Review Manager (version 5.3) using random effects models.

Results: We included 10 studies, which enrolled 1091 patients. The pooled results suggested that patients with larger tumors (diameter $>5 \mathrm{~cm}$ ), lymphovascular invasion, lymph node metastasis, synchronous metastasis and positive margin were prone to suffer from the recurrences of SPTs. In addition, some factors like gender, location of tumors, perineural invasion, calcification and capsular invasion did not show any correlation with the relapses of resected SPTs.

Conclusion: Factors including a larger tumor size (diameter $>5 \mathrm{~cm}$ ), lymphovascular invasion, lymph node metastasis, synchronous metastasis and positive margin may increase the risk of recurrences of resected pancreatic SPTs. All SPTs should be excised and patients with high-risk features should undergo a long-term follow-up.
\end{abstract}

Key words: pancreatic solid pseudopapillary tumors, recurrence, risk factors

\section{Introduction}

Pancreatic solid pseudopapillary neoplasm, originally identified by Frantz in 1959 [1], was defined as solid pseudopapillary tumor (SPT) by the World Health Organization (WHO) in 1996 [2]. SPTs are rare tumors which occupy 1-3 $\%$ of all pancreatic tumors and $10-15 \%$ of cystic tumors of the pancreas [3]. The pathogenesis and cellular derivation are still unknown. An origin from quiescent pancreatic stem cells [4] or genital ridge cells [5] has been proposed. Owing to the advancement in diagnosis, there has 
been a 7-fold increase in the number of SPT cases since 2000 compared with before and they are mainly found in young women [6]. Additionally, symptoms of SPTs are relatively nonspecific [7]. Pooled data showed that overall 5-year survival was excellent ( > $95 \%)$, even in patients with liver metastases (15-20\%) [8]. According to the WHO 2000 histological criteria [9], SPTs were usually benign neoplasms with potential malignancy which could be reflected by precise perineural invasion, angioinvasion, or deep invasion into the surrounding tissue. However, all SPTs were reclassified as low-grade malignant neoplasms in 2010 [10], because they can still present with metastasis and recurrence though they do not have malignant features mentioned above.

Pancreatic SPTs are uncommon tumors with low malignant potential. Due to the low incidence, the majority of literature about SPT was published by case reports. As a result, the true biological behavior of SPTs still remains unknown. Despite the low malignancy, some SPTs did relapse and characteristics according to the WHO criteria could not provide precise prediction of recurrence after surgical resection. Although some risk factors associated with the relapses of resected SPTs have been reported, the results are still controversial. So far, no consensus on the risk factors for the recurrences of SPTs has been established.

The main aim of this study was to identify risk factors for postoperative recurrences in patients with pancreatic SPTs in order to help determine management and follow-up strategies for these patients.

\section{Materials and Methods}

\section{Literature search}

We were intended to identify all relevant studies in spite of language. We searched PubMed, EMBASE, and the Cochrane Library from their inception to December 2017. The search items solid pseudopapillary tumor OR SPT was combined with pancreas and NOT report [Title].

\section{Criteria for inclusion and exclusion}

Studies that

- included patients with pancreatic solid pseudopapillary tumors who underwent surgical resection;

- investigated the recurrences of SPTs after surgery;

- discussed the association between risk factors and the recurrences of SPTs in postoperative patients;
- and were published with full text would be included in this meta-analysis.

The following criteria were applied to exclude studies

- literature reviews or case reports;

- too small sample size $(\mathrm{n}<30)$;

- lack of sufficient or detailed data needed for investigating the recurrence of SPT.

\section{Study selection}

Studies were screened for potential eligibility according to title and abstract by two independent investigators. Then full text of the papers which appeared to be useful after initial scanning were obtained for further evaluation. Disagreement was resolved by consensus.

\section{Quality assessment}

The quality of the included studies was assessed by two independent reviewers according to the Newcastle-Ottawa Quality Assessment Scale (NOS) for case-control studies [11]. The eight elements in the NOS are assessed under three aspects: selection, comparability and exposure. The high-quality choices for each element are marked with one star, and then the quality of each study was evaluated by the total number of stars. The scale assigns a maximum of 9 stars to each study. Studies are considered to be of high quality if they received five stars or more [12].

\section{Data extraction}

All relevant data from included studies were carefully extracted by two independent researchers. Disagreement was resolved by consensus. For each individual study, the following data was extracted:

- General article information: authors, year of publication, country, study design, study period, mean/median age, percentage of female, mean/median follow-up time, number of patients enrolled in the study, number of patients followed up.

- All potential risk factors mentioned in enrolled studies and the number of patients of each group, including age, gender, tumor size, lymphovascular invasion, location, perineural invasion, calcification, lymph node metastasis, synchronous metastasis, positive margin, capsular invasion, presence of capsule, invasion to adjacent extra-pancreatic organs, invasion to peripancreatic tissue, pancreatic fat infiltration, symptom, ki67 index, 2010 criteria, growth pattern, pancreatic parenchyma invasion, abdominal pain, abdominal trauma, tumor rupture, tumor necrosis, stage IV condition, microscopic malignant features, ENETS tumor 
stage, ENETS stage grouping and AJCC stage grouping.

\section{Data synthesis and analysis}

Statistical analyses were performed by Review Manager (version 5.3). Combined ORs with 95\% CIs were calculated for dichotomous data collected from eligible studies. Forest plots were created to show the pooled results. Heterogeneity among combined study results was assessed by Cochran's $Q$ test and by the degree of inconsistency $\left(\mathrm{I}^{2}\right)$ [13]. Heterogeneity would be considered significant if the P-value for Cochran's $Q$ test was less than or equal to 0.1. As for $\mathrm{I}^{2}$, high heterogeneity was defined as greater than $70 \%$, medium heterogeneity was defined as $50 \%-70 \%$, and low heterogeneity was defined as $0 \%-50 \%$ [14]. Relevant data was quantitatively summarized when a factor was investigated in at least three studies. Random effects models were applied because they can provide more conservative results [15]. Publication bias was descriptively assessed by funnel plot [16]. Furthermore, subgroup and sensitivity analyses would be performed if necessary. P-value < 0.05 was considered statistically significant.

\section{Results}

\section{Study selection}

The study selection and identification progress was shown in Fig. 1. 887 records were identified after initial search. By screening title and abstract, 842 records were excluded and then 45 full-text articles were assessed for eligibility. Finally, 10 studies were eligible and enrolled in this meta-analysis. Other articles were excluded due to the following reasons: (a) literature reviews; (b) too small sample size ( $\mathrm{n}$ < 30); (c) lacking significant data because they did not focus on the recurrences of SPTs in postoperative patients; (d) reselecting patients with stricter criteria after initial selection.

\section{General study characteristics}

The general characteristics of the included studies are presented in Table 1. A total of 1091 patients were included in these studies. All of them were retrospective cohort studies. 2 studies were performed in China [17, 18], 3 studies were performed in South Korea [19-21], 1 study was performed in Brazil [22], 1 study was performed in Canada [23], 1 study was performed in France [24], 1 study was performed in Italy and America [25] and 1 study was performed in America [26].

\section{Quality of studies}

Quality assessment of the included studies is shown in Table 1. All studies were of high quality. Studies mainly lost stars for comparability because the number of patients in experimental group was relatively small. Studies also lost stars for selection because patients enrolled were limited to single center.

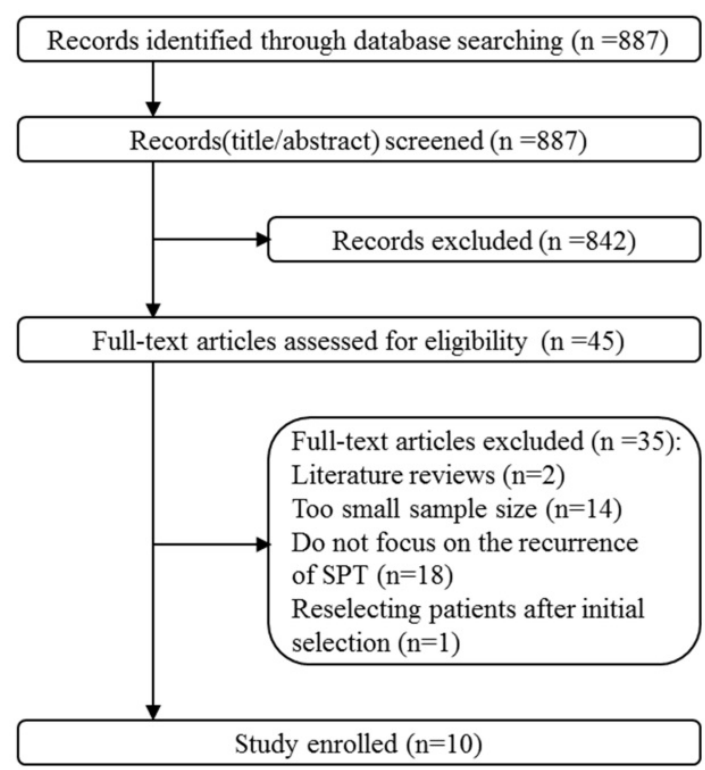

Figure 1. The flowchart of literature searching and selection.

Table 1. General characteristics of enrolled studies.

\begin{tabular}{|c|c|c|c|c|c|c|c|c|c|c|}
\hline Author & Year & Country & study design & Study period & $\begin{array}{l}\text { Total } \\
\text { cases }\end{array}$ & $\begin{array}{l}\text { Cases } \\
\text { followed up }\end{array}$ & $\begin{array}{l}\text { Female } \\
(\%)\end{array}$ & $\begin{array}{l}\text { Mean age } \\
\text { (years) }\end{array}$ & $\begin{array}{l}\text { Mean follow } \\
\text { up time (months) }\end{array}$ & NOS \\
\hline Xu et al.[17] & 2017 & China & retrospective & $2008-2015$ & 121 & 103 & 76.9 & 33.7 & 42.7 & 7 \\
\hline Xu et al.[18] & 2016 & China & retrospective & 2006-2014 & 148 & 116 & 79.1 & 30.8 & 32.6 & 7 \\
\hline Marchegiani et al.[25] & 2016 & Italy, USA & retrospective & 1986-2014 & 131 & 105 & 86.3 & $33^{*}$ & $62^{*}$ & 8 \\
\hline Irtan et al.[24] & 2016 & France & retrospective & 1996-2016 & 51 & 51 & 78 & $13.1^{*}$ & $65^{*}$ & 7 \\
\hline Serrano et al.[23] & 2014 & Canada & retrospective & $1999-2013$ & 32 & 32 & 81.25 & 35.65 & $43^{*}$ & 7 \\
\hline Kang et al.[19] & 2014 & South Korea & retrospective & $1990-2008$ & 351 & 317 & 90.3 & 36.8 & Not mentioned & 8 \\
\hline Hwang et al.[20] & 2014 & South Korea & retrospective & 1992-2012 & 45 & 45 & 80 & 14.9 & $34^{*}$ & 6 \\
\hline Estrella et al.[26] & 2014 & USA & retrospective & Not mentioned & 64 & 59 & 84 & 33 & $76^{*}$ & 7 \\
\hline Kim et al.[21] & 2011 & South Korea & retrospective & 1995-2007 & 114 & 114 & 86.9 & $36^{*}$ & $57^{*}$ & 7 \\
\hline Machado et al.[22] & 2008 & Brazil & retrospective & 1990-2005 & 34 & 34 & 79 & $23^{*}$ & 84 & 7 \\
\hline
\end{tabular}

USA: the United States of America; *median; NOS: the Newcastle-Ottawa Quality Assessment Scale. 


\section{Outcomes}

\section{Gender}

Data on gender was pooled for eight studies [17, 19-24, 26]. The pooled data suggested that gender did not have any influence on the postoperative recurrences of SPTs (OR: 0.75 [0.30, 1.88]; $\mathrm{P}=0.54$ ) (Fig. 2A). Heterogeneity was low $\left(\mathrm{P}=0.96 ; \mathrm{I}^{2}=0 \%\right)$. A sensitivity analysis was conducted by a fixed effects model. The pooled OR was $0.70[0.29,1.71](p=0.43)$.

\section{Tumor size}

Five studies reported on tumor size according to two criteria, diameter $>5 \mathrm{~cm}[17,18,26]$ and $8 \mathrm{~cm}[19$, $24,26]$, respectively. The combined results indicated that larger tumor size might increase the risk of postoperative recurrences of SPTs regardless of different criteria (OR: 4.74 [1.12, 20.05]; $\mathrm{P}=0.03$ (Fig. 2B). OR: 6.11 [2.29, 16.27]; $\mathrm{P}=0.0003$ (Fig. 2C)). Sensitivity analyses were conducted using fixed effects models. The pooled ORs were 5.22 [1.28, 21.26] $(p=0.02)$ and $5.99[2.27,15.80](p=0.0003)$. Heterogeneity of both of them was low $\left(\mathrm{P}=0.75 ; \mathrm{I}^{2}=\right.$ $\left.0 \% . \mathrm{P}=0.50 ; \mathrm{I}^{2}=0 \%\right)$.

\section{Location}

Location of tumor was investigated in six studies $[17,19-21,24,26]$. In the present study, pancreas was divided into two parts: proximal pancreas (PP) including uncinate process, head and neck and distal pancreas (DP) including body and tail. The pooled results suggested that the location of tumor did not show any correlation with the risk of postoperative relapses of SPTs (OR: 0.58 [0.26, 1.28]; $\mathrm{P}=0.17$ ) (Fig. 3A). A sensitivity analysis was conducted by a fixed effects model. The pooled OR was $0.53[0.24,1.14](\mathrm{p}=$ $0.10)$. Heterogeneity was low $\left(P=0.79 ; I^{2}=0 \%\right)$.

\section{Lymphovascular invasion}

Data on the lymphovascular invasion of tumor was reported by five studies [17, 23-26]. The combined data suggested that lymphovascular invasion could increase the risk of postoperative relapses of SPTs (OR: 10.54 [3.50, 31.77]; $\mathrm{P}<0.0001$ ) (Fig. 3B). A sensitivity analysis was conducted using a fixed effects model. The pooled OR was $9.14[3.10,26.92]$ ( $p$ $<0.0001)$. Heterogeneity was low $\left(P=0.62 ; \mathrm{I}^{2}=0 \%\right)$.

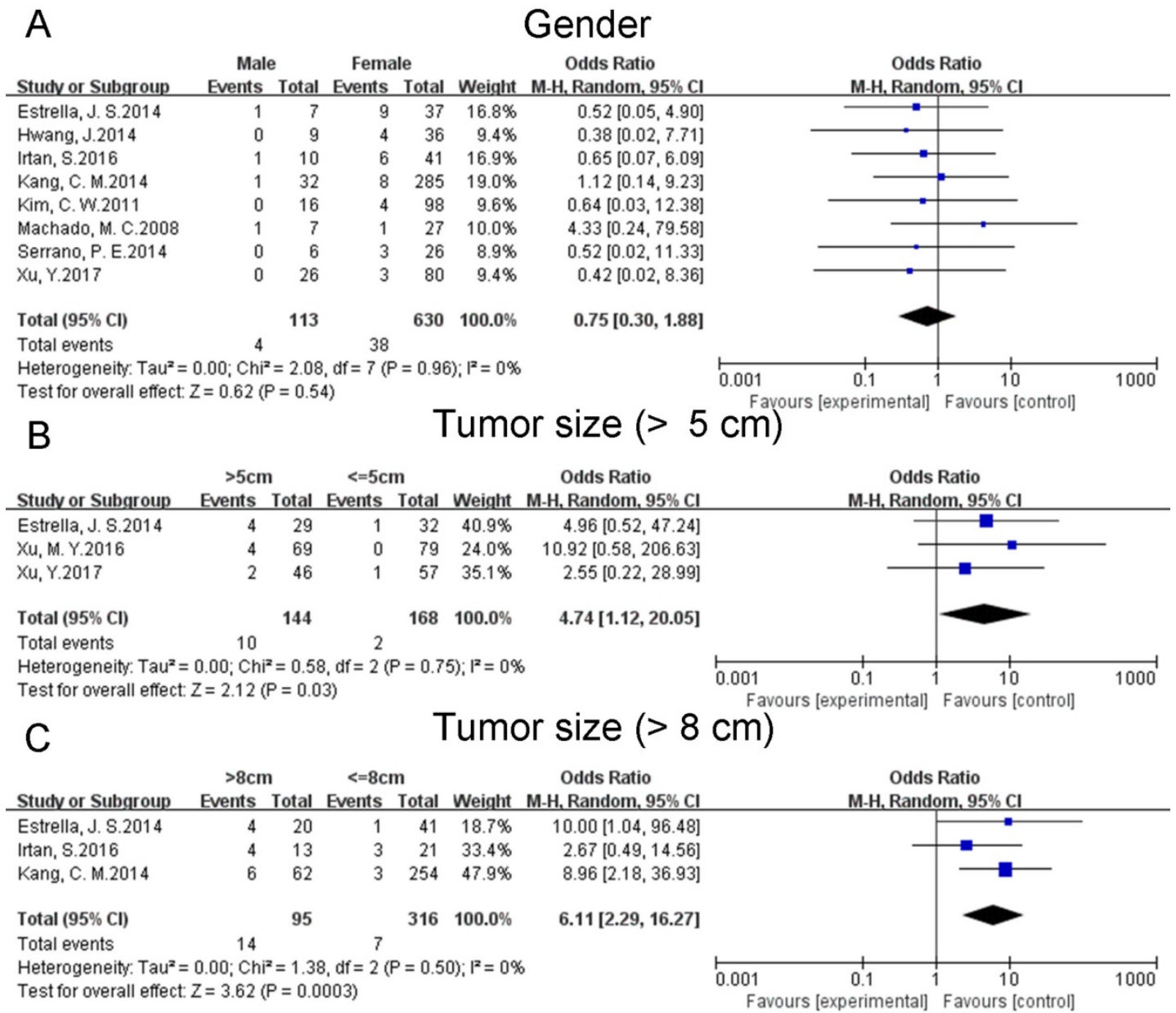

Figure 2. Forest plots of association between relevant factors and recurrence of SPT. A: the association between the recurrence of SPT and gender. B: the association between the recurrence of SPT and tumor size (diameter $>5 \mathrm{~cm})$. C: the association between the recurrence of SPT and tumor size $($ diameter $>8 \mathrm{~cm})$. 
A

Location

\begin{tabular}{|c|c|c|c|c|c|c|c|c|c|c|}
\hline Study or Subgroup & $\begin{array}{l}\text { Pp } \\
\text { Events }\end{array}$ & Total & $\begin{array}{r}\text { DP } \\
\text { Events }\end{array}$ & Total & Weight & $\begin{array}{c}\text { Odds Ratio } \\
\text { M-H, Random, } 95 \% \mathrm{Cl}\end{array}$ & & $\begin{array}{r}\text { Odds F } \\
\text { M-H, Rando }\end{array}$ & $\begin{array}{l}\text { Ratio } \\
\text { lom. } 95 \% \mathrm{Cl}\end{array}$ & \\
\hline Estrella, J. S.2014 & 1 & 13 & 9 & 31 & $13.3 \%$ & $0.20[0.02,1.81]$ & & & T & \\
\hline Hwang, J.2014 & 1 & 16 & 3 & 29 & $11.4 \%$ & $0.58[0.06,6.06]$ & & & & \\
\hline Irtan, S.2016 & 3 & 26 & 4 & 25 & $24.4 \%$ & $0.68[0.14,3.42]$ & & & & \\
\hline Kang, C. M.2014 & 3 & 98 & 6 & 219 & $31.9 \%$ & $1.12[0.27,4.58]$ & & & & \\
\hline Kim, C.W.2011 & 1 & 49 & 3 & 64 & $12.0 \%$ & $0.42[0.04,4.20]$ & & & & \\
\hline$X u, Y .2017$ & 0 & 43 & 3 & 60 & $7.1 \%$ & $0.19[0.01,3.75]$ & & & & \\
\hline Total $(95 \% \mathrm{Cl})$ & & 245 & & 428 & $100.0 \%$ & $0.58[0.26,1.28]$ & & & & \\
\hline Total events & 9 & & 28 & & & & & & & \\
\hline \multicolumn{7}{|c|}{$\begin{array}{l}\text { Heterogeneity: } \text { Tau }^{2}=0.00 ; \mathrm{Chi}^{2}=2.43, \mathrm{df}=5(P=0.79) ; \mathrm{I}^{2}=0 \% \\
\text { Test for overall effect: } Z=1.36(P=0.17)\end{array}$} & 0.001 & 0.1 & 10 & $1000^{\circ}$ \\
\hline
\end{tabular}

B

\section{Lymphovascular invasion}

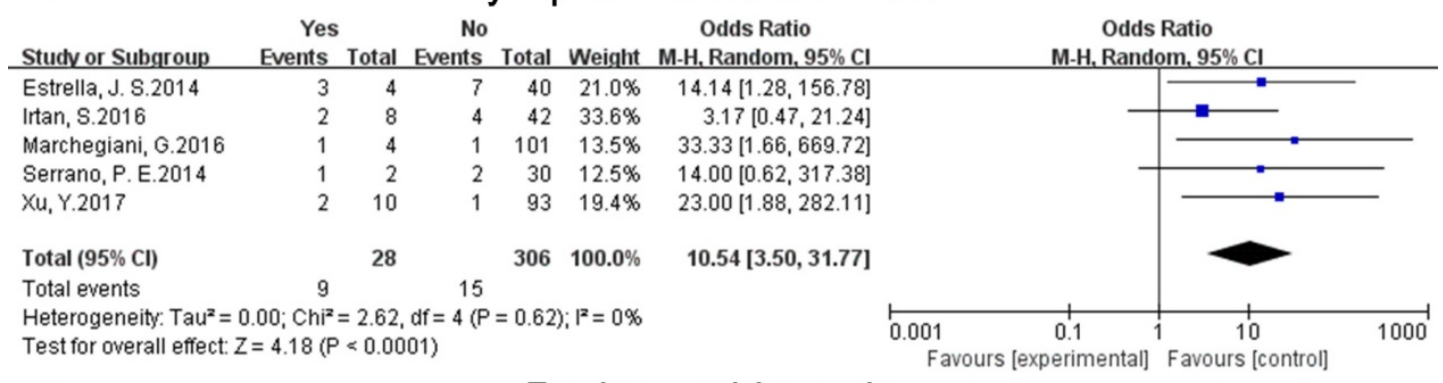

C

Perineural invasion

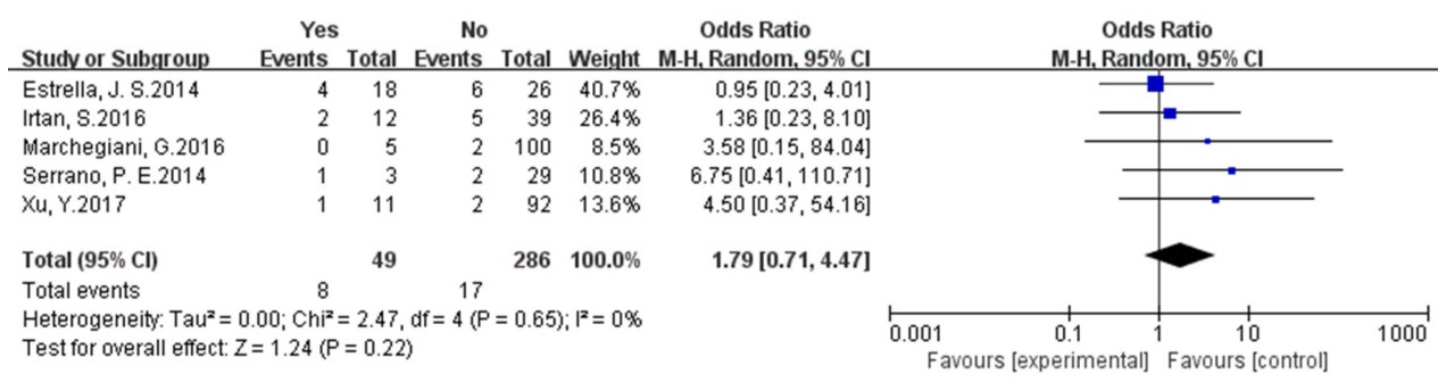

Figure 3. Forest plots of association between relevant factors and recurrence of SPT. A: the association between the recurrence of SPT and location. B: the association between the recurrence of SPT and lymphovascular invasion. C: the association between the recurrence of SPT and perineural invasion.

\section{Perineural invasion}

Data on the perineural invasion of tumor was available for five studies [17, 23-26]. The pooled results showed that perineural invasion did not increase or decrease the risk of postoperative recurrences of SPTs (OR: 1.79 [0.71, 4.47]; $\mathrm{P}=0.22$ ) (Fig. 3C). A sensitivity analysis was conducted by a fixed effects model. The pooled OR was 1.60 [0.63, 4.03] $(\mathrm{p}=0.32)$. Heterogeneity was low $\left(\mathrm{P}=0.65 ; \mathrm{I}^{2}=\right.$ $0 \%)$.

\section{Calcification}

Three studies [20, 23, 25] discussed the calcification of tumor. The combined data reflected that calcification did not influence the risk of postoperative recurrences of SPTs (OR: 0.60 [0.10, 3.55]; $\mathrm{P}=0.57$ ) (Fig. 4A). A sensitivity analysis was conducted using a fixed effects model. The pooled OR was $0.56[0.09,3.25](p=0.51)$. Heterogeneity was low $\left(\mathrm{P}=0.82 ; \mathrm{I}^{2}=0 \%\right)$

\section{Lymph node metastasis}

Lymph node metastasis of tumor was examined in five studies [17, 23-26]. The pooled results indicated that lymph node metastasis might increase the risk of postoperative relapses of SPTs (OR: 6.58 [1.92, 22.57]; $\mathrm{P}=0.003$ ) (Fig. 4B). A sensitivity analysis was conducted using a fixed effects model. The pooled OR was $5.89[1.76,19.72](p=0.004)$. Heterogeneity was low $\left(\mathrm{P}=0.76 ; \mathrm{I}^{2}=0 \%\right)$.

\section{Synchronous metastasis}

Three studies [17, 23, 25] investigated the synchronous metastasis of tumor. The combined data suggested that synchronous metastasis could increase the risk of postoperative recurrences of SPTs (OR: 103.21 [8.20, 1298.97]; $\mathrm{P}=0.0003$ ) (Fig. 4C). A sensitivity analysis was conducted by a fixed effects model. The pooled OR was 100.83 [17.84, 569.85] $(\mathrm{p}<$ $0.00001)$. Heterogeneity was low $\left(\mathrm{P}=0.23 ; \mathrm{I}^{2}=31 \%\right)$. 


\section{Positive margin}

Data on the margin status was pooled for six studies [19, 21, 23-26]. The pooled results reflected that positive margin might increase the risk of postoperative relapses of SPTs (OR: 6.78 [2.44, 18.78];
$P=0.0002)$ (Fig. 5A). A sensitivity analysis was conducted using a fixed effects model. The pooled OR was $6.82[2.51,18.55](p=0.0002)$. Heterogeneity was low $\left(\mathrm{P}=0.96 ; \mathrm{I}^{2}=0 \%\right)$.

A

Calcification

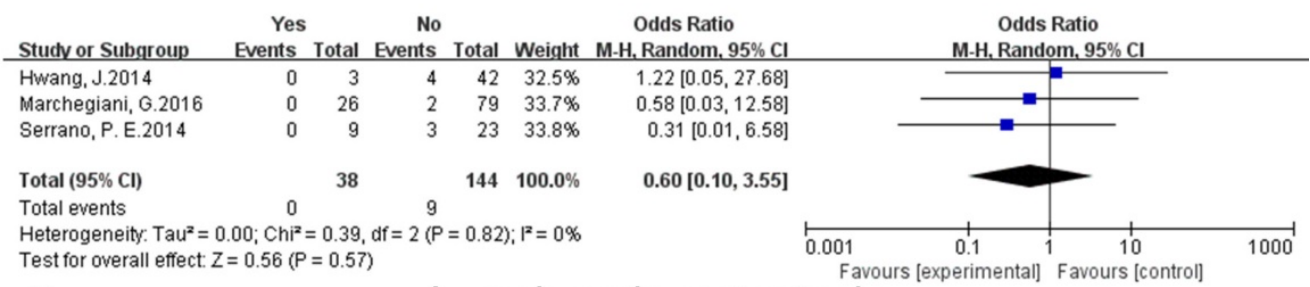

B

Lymph node metastasis

\begin{tabular}{|c|c|c|c|c|c|c|c|c|c|c|}
\hline Study or Subgroup & $\begin{array}{c}\text { Yes } \\
\text { Events }\end{array}$ & Total & $\begin{array}{r}\text { No } \\
\text { Events }\end{array}$ & Total & Weight & $\begin{array}{c}\text { Odds Ratio } \\
\mathrm{M}-\mathrm{H} \text {. Random, } 95 \% \mathrm{Cl}\end{array}$ & & $\begin{array}{r}\text { Odds F } \\
\text { M-H. Rando }\end{array}$ & $\begin{array}{l}\text { Ratio } \\
\text { om, } 95 \% \mathrm{Cl}\end{array}$ & \\
\hline Estrella, J. S.2014 & 3 & 6 & 7 & 38 & $47.0 \%$ & $4.43[0.73,26.74]$ & & & $=$ & \\
\hline Irtan, S.2016 & 0 & 1 & 7 & 50 & $14.0 \%$ & $1.93[0.07,52.06]$ & & & & \\
\hline Marchegiani, G.2016 & 0 & 1 & 2 & 104 & $12.9 \%$ & $13.67[0.44,425.25]$ & & & & \\
\hline Serrano, P.E.2014 & 1 & 1 & 2 & 31 & $12.8 \%$ & $35.40[1.12,1116.44]$ & & & & \\
\hline$X u, Y .2017$ & 0 & 1 & 3 & 102 & $13.4 \%$ & $9.48[0.32,276.50]$ & & & & \\
\hline Total $(95 \% \mathrm{Cl})$ & & 10 & & 325 & $100.0 \%$ & $6.58[1.92,22.57]$ & & & & \\
\hline Total events & 4 & & 21 & & & & & & & \\
\hline $\begin{array}{l}\text { Heterogeneity: } \operatorname{Tau}^{2}= \\
\text { Test for overall effect: }\end{array}$ & $\begin{array}{l}00 ; \mathrm{Chi}^{2}= \\
=2.99(\mathrm{P}\end{array}$ & $\begin{array}{l}=1.88 \\
=0.00\end{array}$ & $\begin{array}{l}d f=4(P= \\
3)\end{array}$ & $=0.76$, & $; 1^{2}=0 \%$ & & 0.001 & 0.11 & $\begin{array}{r}10 \\
\text { ours Ic }\end{array}$ & 1000 \\
\hline
\end{tabular}

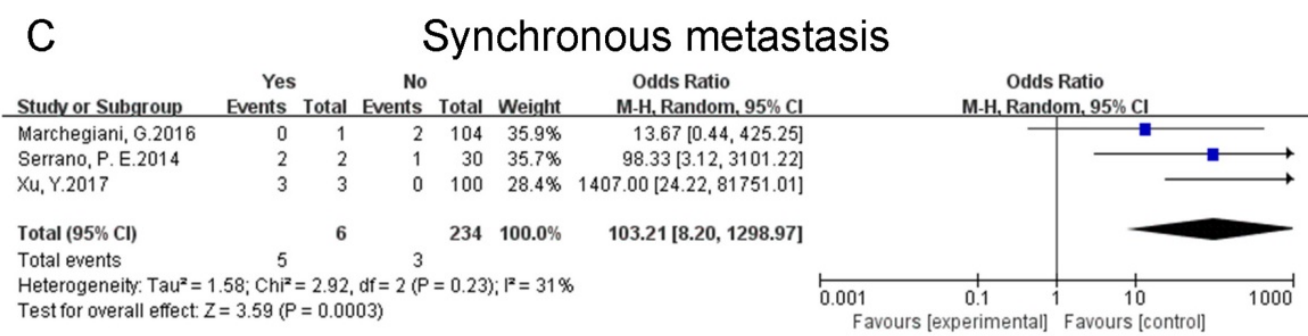

Figure 4. Forest plots of association between relevant factors and recurrence of SPT. A: the association between the recurrence of SPT and calcification. B: the association between the recurrence of SPT and lymph node metastasis. C: the association between the recurrence of SPT and synchronous metastasis.

A

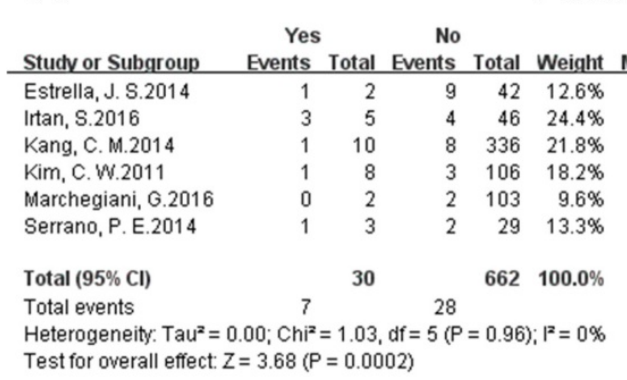

\section{Positive margin}

Odds Ratio

, Random, $95 \% \mathrm{Cl}$ $3.67[0.21,64.55]$ $15.75[2.00,123.86]$ $4.56[0.51,40.37]$ $4.90[0.45,53.48]$ $8.12[0.30,216.97$ $6.75[0.41,110.71]$

$6.78[2.44,18.78]$

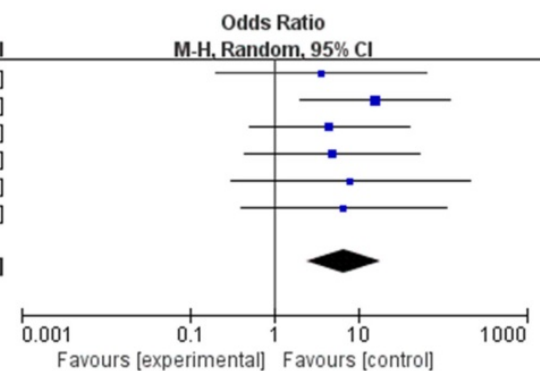

B

Capsular invasion

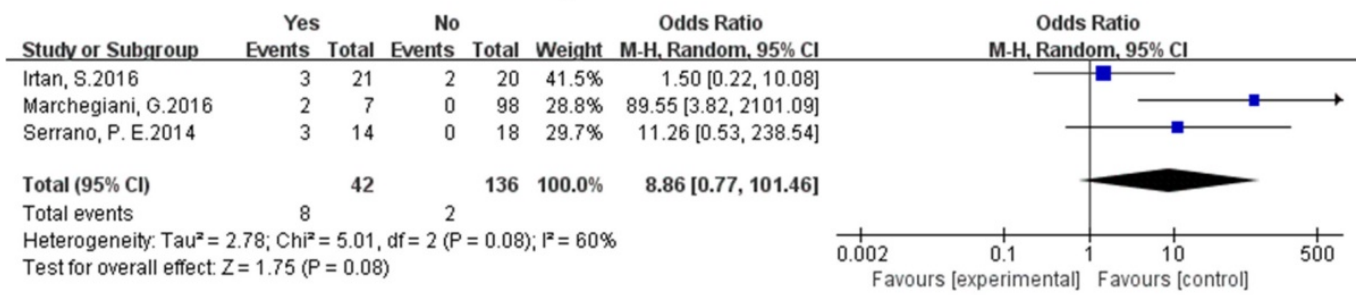

Figure 5. Forest plots of association between relevant factors and recurrence of SPT. A: the association between the recurrence of SPT and positive margin. B: the association between the recurrence of SPT and capsular invasion. 


\section{Capsular invasion}

Three studies [23-25] mentioned the capsular invasion of tumor. The pooled data indicated that capsular invasion do not have any correlation with the risk of recurrences of resected SPTs (OR: 8.86 [0.77, 101.46]; $\mathrm{P}=0.08$ ) (Fig. 5B). A sensitivity analysis was conducted by a fixed effects model. The pooled OR was $5.15[1.38,19.18](p=0.01)$. Heterogeneity was medium $\left(\mathrm{P}=0.08 ; \mathrm{I}^{2}=60 \%\right)$. Given that only three studies focused on this factor, subgroup analysis was unfeasible.

\section{Other factors}

Data on the age of patients was available for seven studies [17, 19-21, 23, 24, 26], while most of them was shown by mean or median age, therefore pooled results were unavailable. Some factors investigated only in one or two studies could not be summarized quantitatively. Xu et al [17] reported that high-grade malignant tumor according to the WHO 2010 classification and peripancreatic fat infiltration could be used to estimate the relapses of SPTs. Marchegiani et al [25] found that an infiltrative growth pattern and pancreatic parenchyma invasion might increase the risk of postoperative recurrences of SPTs. According to Irtan et al [24], age under 13.5 years at diagnosis was a risk factor of postoperative relapses of SPTs. A report from Serrano et al [23] showed that invasion to adjacent extra-pancreatic organs could increase the risk of the recurrences of resected SPTs. Kang et al [19] considered that microscopic malignant features was significantly associated with the relapses of SPTs. Presence of capsule was discussed in two studies $[23,24]$ and both of them suggested that no significant influence of capsule of tumor was found. A study by Kang et al [19] indicated that the presence of clinical symptoms might predict the relapses of SPTs, while Kim et al [21] reported the contrary result. Estrella et al [26] discovered that ENETS tumor stage, ENETS stage grouping and AJCC stage grouping were significant predictors of the postoperative recurrences of SPTs. Kang et al [19] suggested that stage IV condition (peritoneal seeding and distant metastasis) was a predictive factor for recurrences of resected SPTs. In additional to the factors mentioned above, the ki67 index [17], invasion to peripancreatic tissue [24], abdominal pain [24], abdominal trauma [24], tumor rupture [24] and tumor necrosis [24] were not found statistically related to the recurrences of resected SPTs.

\section{Publication bias}

Given that a funnel plot should be based on at least 10 studies [27], publication bias (Fig. 6) was considered as unclear due to the limited number of included studies.

\section{Discussion}

This is a systematic review and meta-analysis that assessed the risk factors for postoperative recurrences in patients with pancreatic SPTs. The pooled results indicated that patients with larger tumors (diameter $>5 \mathrm{~cm}$ ), lymphovascular invasion, lymph node metastasis, synchronous metastasis and positive margin were prone to surfer from the recurrences of SPTs. In addition, some factors like gender, location of tumors, perineural invasion, calcification and capsular invasion did not increase or decrease the risk of the relapses of resected SPTs. We also identified many other factors associated with the postoperative recurrences of pancreatic SPTs, such as age, presence of capsule, invasion to adjacent extrapancreatic organs, invasion to peripancreatic tissue, pancreatic fat infiltration, symptom, ki67 index, 2010 criteria, growth pattern, pancreatic parenchyma invasion, abdominal pain, abdominal trauma, tumor rupture, tumor necrosis, stage IV condition, microscopic malignant features, ENETS tumor stage, ENETS stage grouping and AJCC stage grouping. However, the effects of these factors might be inconclusive due to the limited number of studies investigating them.

SPTs of the pancreas are rare neoplasms with low-grade malignancy. Most of them present with nonspecific symptoms, such as abdominal discomfort or pain. Owing to the covert manifestations, pancreatic SPTs are usually picked up by imaging examinations [28]. Typical imaging characteristics of pancreatic SPTs are described as encapsulated masses with solid and cystic components and frequent internal hemorrhage [29]. Although SPTs have typical radiological features, some of them were still preoperatively misdiagnosed for pancreatic cystic neoplasms [23]. As for the confusion between pancreatic SPTs and cystic neoplasms, histological differential diagnosis is crucial [30]. Atypical imaging features including vascular invasion and invasion into surrounding pancreatic parenchyma, peripancreatic tissues and adjacent organs [31] are considered to be relevant with their aggressive behavior, which may cause the tumors to be prone to recur. Similarly, aggressive behavior of SPT is also characterized by some certain pathological features. According to WHO 2000 criteria, SPTs are identified as malignant with perineural invasion, vascular invasion and invasion into peripancreatic tissues. WHO 2010 criteria has defined all SPTs as low-grade malignant. In addition, SPTs possess high-grade malignancy, which is indicated by lesions with diffuse growth patterns, increased nuclear atypia, relatively abundant mitosis, and sarcomatoid carcinoma. 


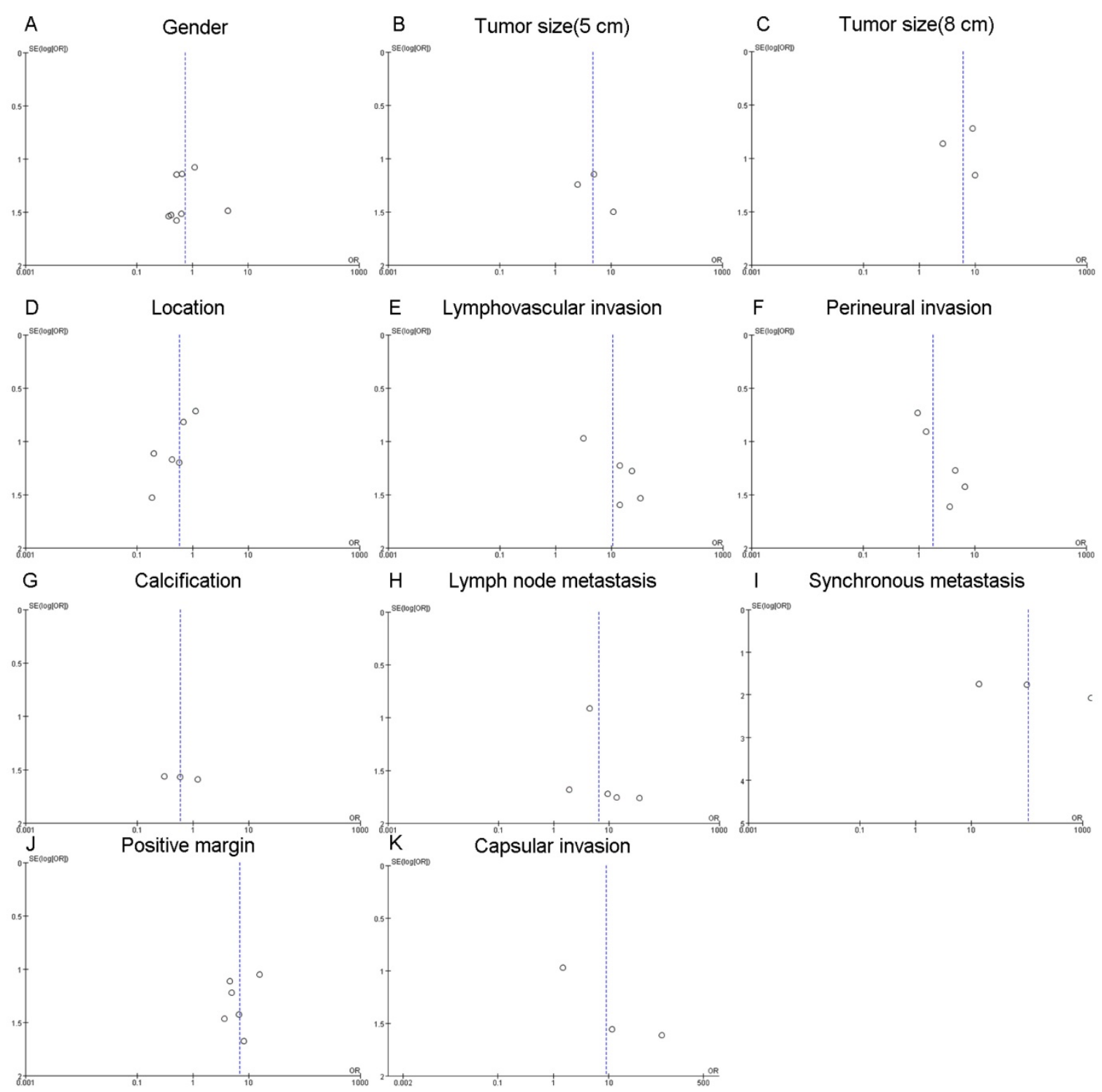

Figure 6. Funnel plots for publication bias. A: the funnel plot of gender. B: the funnel plot of tumor size (diameter $>5 \mathrm{~cm}$ ). C: the funnel plot of tumor size (diameter $>8 \mathrm{~cm}$ ). D: the funnel plot of location. E: the funnel plot of lymphovasular invasion. F: the funnel plot of perineural invasion. G: the funnel plot of calcification. H: the funnel plot of lymph node metastasis. I: the funnel plot of synchronous metastasis. J: the funnel plot of positive margin. K: the funnel plot of capsular invasion.

Since the incidence of pancreatic SPTs is low, no guidelines for clinical management and follow-up strategies have been clearly established. Surgical resection is still the main treatment and combination of surgical resection and chemotherapy is also applied [32]. Despite the low malignant potential, $9-15 \%$ of them present with metastasis or local invasion [33]. As a result, all SPTs should be recommended for resection even in patients with metastasis because these patients could still obtain good prognosis [34]. Given that previous reports have found their late recurrence patterns [21, 35] and most relapses occurred more than 5 years after resection, a $>5$-year follow-up is necessary after resections of SPTs with high-risk features (larger tumors (diameter $>5 \mathrm{~cm}$ ), lymphovascular invasion, lymph node metastasis, synchronous metastasis and positive margin). Additionally, surgical resection of tumor recurrence could still provide good long-term results [21, 23].

The present study has some strengths and limitations. One of the strengths is the presence of low statistical heterogeneity in all combined results except the medium heterogeneity of capsular invasion. Additionally, random effects models were applied in this meta-analysis to acquire more conservative results. Our results were certified to be robust across various sensitivity analyses by fixed effects models (Table 2). 
Table 2. Pooled results and sensitivity analyses.

\begin{tabular}{|c|c|c|c|c|c|c|c|}
\hline $\begin{array}{l}\text { Risk } \\
\text { factors }\end{array}$ & $\begin{array}{l}\text { Number } \\
\text { of studies }\end{array}$ & $\begin{array}{l}\text { Effects } \\
\text { model }\end{array}$ & OR & $95 \% \mathrm{CI}$ & $\mathbf{P}$ & $\mathbf{I}^{2}$ & $\mathbf{P}_{\mathbf{H}}$ \\
\hline \multirow[t]{2}{*}{ Gender } & \multirow[t]{2}{*}{8} & Random & 0.75 & $0.30-1.88$ & 0.54 & $0 \%$ & 0.96 \\
\hline & & Fixed* & 0.70 & $0.29-1.71$ & 0.43 & $0 \%$ & 0.96 \\
\hline \multirow{2}{*}{$\begin{array}{l}\text { Tumor size } \\
(5 \mathrm{~cm})\end{array}$} & \multirow[t]{2}{*}{3} & Random & 4.74 & $1.12-20.05$ & 0.03 & $0 \%$ & 0.75 \\
\hline & & Fixed $^{*}$ & 5.22 & $1.28-21.26$ & 0.02 & $0 \%$ & 0.75 \\
\hline \multirow{2}{*}{$\begin{array}{l}\text { Tumor size } \\
(8 \mathrm{~cm})\end{array}$} & \multirow[t]{2}{*}{3} & Random & 6.11 & $2.29-16.27$ & 0.0003 & $0 \%$ & 0.5 \\
\hline & & Fixed $^{*}$ & 5.99 & $2.27-15.80$ & 0.0003 & $0 \%$ & 0.5 \\
\hline \multirow[t]{2}{*}{ Location } & \multirow[t]{2}{*}{6} & Random & 0.58 & $0.26-1.28$ & 0.17 & $0 \%$ & 0.79 \\
\hline & & Fixed $^{*}$ & 0.53 & $0.24-1.14$ & 0.10 & $0 \%$ & 0.79 \\
\hline \multirow{2}{*}{$\begin{array}{l}\text { Lymphovasc } \\
\text { ular invasion }\end{array}$} & \multirow[t]{2}{*}{5} & Random & 10.54 & $3.50-31.77$ & $<0.0001$ & $0 \%$ & 0.62 \\
\hline & & Fixed $^{*}$ & 9.14 & $3.10-26.92$ & $<0.0001$ & $0 \%$ & 0.62 \\
\hline \multirow{2}{*}{$\begin{array}{l}\text { Perineural } \\
\text { invasion }\end{array}$} & \multirow[t]{2}{*}{5} & Random & 1.79 & $0.71-4.47$ & 0.22 & $0 \%$ & 0.65 \\
\hline & & Fixed $^{*}$ & 1.60 & $0.63-4.03$ & 0.32 & $0 \%$ & 0.65 \\
\hline \multirow[t]{2}{*}{ Calcification } & \multirow[t]{2}{*}{3} & Random & 0.60 & $0.10-3.55$ & 0.57 & $0 \%$ & 0.82 \\
\hline & & Fixed $^{*}$ & 0.56 & $0.09-3.25$ & 0.51 & $0 \%$ & 0.82 \\
\hline \multirow{2}{*}{$\begin{array}{l}\text { Lymph node } \\
\text { metastasis }\end{array}$} & \multirow[t]{2}{*}{5} & Random & 6.58 & $1.92-22.57$ & 0.003 & $0 \%$ & 0.76 \\
\hline & & Fixed $^{*}$ & 5.89 & $1.76-19.72$ & 0.004 & $0 \%$ & 0.76 \\
\hline \multirow[t]{2}{*}{$\begin{array}{l}\text { Synchronous } \\
\text { metastasis }\end{array}$} & \multirow[t]{2}{*}{3} & Random & $\begin{array}{l}103.2 \\
1\end{array}$ & $8.20-1298.97$ & 0.0003 & $\begin{array}{l}31 \\
\%\end{array}$ & 0.23 \\
\hline & & Fixed* & $\begin{array}{l}100.8 \\
3\end{array}$ & $17.84-568.85$ & $\begin{array}{l}<0.0000 \\
1\end{array}$ & $\begin{array}{l}31 \\
\%\end{array}$ & 0.23 \\
\hline \multirow{2}{*}{$\begin{array}{l}\text { Positive } \\
\text { margin }\end{array}$} & \multirow[t]{2}{*}{6} & Random & 6.78 & $2.44-18.78$ & 0.0002 & $0 \%$ & 0.96 \\
\hline & & Fixed* & 6.82 & $2.51-18.55$ & 0.0002 & $0 \%$ & 0.96 \\
\hline \multirow[t]{2}{*}{$\begin{array}{l}\text { Capsular } \\
\text { invasion }\end{array}$} & \multirow[t]{2}{*}{3} & Random & 8.86 & $0.77-101.46$ & 0.08 & $\begin{array}{l}60 \\
\%\end{array}$ & 0.08 \\
\hline & & Fixed* & 5.15 & $1.38-19.18$ & 0.01 & $\begin{array}{l}60 \\
\%\end{array}$ & 0.08 \\
\hline
\end{tabular}

*sensitivity analysis

This study also has several limitations. First of all, the summarized results are based on only 10 or fewer studies. Some reasons may be responsible for this shortcoming. On one hand, relatively few studies investigated the risk factors associated with the relapses of resected pancreatic SPTs. Therefore, additional well-designed studies about potential risk factors of the recurrences of SPTs are greatly needed. On the other hand, some potentially eligible studies may not be included. Secondly, enrolled studies had limitations. Most of them [17, 18, 20, 21, 23, 26] were based on single institution. Two of them [20,21] were based on the same hospital, though the study period and criteria including patients were different. Patients of two studies were limited to pediatric patients [24] and patients $\leq 20$ years old [20]. Only data on gender was available in one study [22]. Similarly, $\mathrm{Xu}$ et al[18] only investigated the association between tumor size and the relapses of resected SPTs. Thirdly, due to the low incidence rate of pancreatic SPTs, the number of patients in experimental group was relatively small, which leads the comparability between experimental group and control group was weak.

\section{Conclusion}

This meta-analysis provided comprehensive evidence that larger tumors (diameter $>5 \mathrm{~cm}$ ), lymphovascular invasion, lymph node metastasis, synchronous metastasis and positive margin could increase the risk of postoperative recurrences of pancreatic SPTs. Due to the low but actual malignant potential, all SPTs should be excised, which could provide positive prognosis. Patients in high-risk subtype should undergo > 5-year follow-up with routine examinations, especially considering that resection of relapse can still offer a hopeful prognosis and these patients can obtain long-term survivals. Because of the limitations of our study, more and further research regarding this topic are called for, especially well-designed studies with large sample sizes.

\section{Abbreviations}

SPT: solid pseudopapillary tumor; WHO: World Health Organization.

\section{Acknowledgements}

This work was supported in part by grants from the National Natural Science Foundation of China (81672449), the Innovation Capability Development Project of Jiangsu Province (BM2015004), the Priority Academic Program Development of Jiangsu Higher Education Institutions (PAPD, JX10231801), and the Jiangsu Key Medical Discipline (General Surgery) (ZDXKA2016005).

\section{Authors' contributions}

MY designed this study and modified this manuscript. GH performed the study and wrote this paper. GY and YLD collected the data and assessed the quality of included studies. WGF, WJS and JKR were responsible for the analysis of pooled data.

\section{Competing Interests}

The authors have declared that no competing interest exists.

\section{References}

1. Frantz VK. Tumors of the pancreas. Atlas of tumor pathology Washington, DC: Armed forces Institute of Pathology. 1959: 32-3.

2. Kloppel G, Heitz PU, Capella C, Solcia E. Pathology and nomenclature of human gastrointestinal neuroendocrine (carcinoid) tumors and related lesions. World journal of surgery. 1996; 20: 132-41.

3. Yu P, Cheng X, Du Y, Yang L, Xu Z, Yin W, et al. Solid Pseudopapillary Neoplasms of the Pancreas: a 19-Year Multicenter Experience in China. J Gastrointest Surg. 2015; 19: 1433-40.

4. Galmiche L, Sarnacki S, Verkarre V, Boizet B, Duvillie B, Fabre M, et al. Transcription factors involved in pancreas development are expressed in paediatric solid pseudopapillary tumours. Histopathology. 2008; 53: 318-24.

5. Kosmahl M, Seada LS, Janig U, Harms D, Kloppel G. Solid-pseudopapillary tumor of the pancreas: its origin revisited. Virchows Archiv : an international journal of pathology. 2000; 436: 473-80.

6. Law JK, Ahmed A, Singh VK, Akshintala VS, Olson MT, Raman SP, et al. A systematic review of solid-pseudopapillary neoplasms: are these rare lesions? Pancreas. 2014; 43: 331-7.

7. Bhutani N, Kajal P, Singla S, Sangwan V. Solid pseudopapillary tumor of the pancreas: Experience at a tertiary care centre of Northern India. Int J Surg Case Rep. 2017; 39: 225-30.

8. Papavramidis T, Papavramidis S. Solid pseudopapillary tumors of the pancreas: review of 718 patients reported in English literature. J Am Coll Surg. 2005; 200: 965-72.

9. Hamilton SR, Aaltonen L.A. Pathology and genetics of tumors of the digestive system IARC Press. 2000 
10. Bosman FT, Carneiro F., Hruban R.H., Theise N.D. WHO Classification of Tumours of the Digestive System, 4th ed. IARC Press. 2010.

11. Stang A. Critical evaluation of the Newcastle-Ottawa scale for the assessment of the quality of nonrandomized studies in meta-analyses. European journal of epidemiology. 2010; 25: 603-5.

12. Das SL, Singh PP, Phillips AR, Murphy R, Windsor JA, Petrov MS. Newly diagnosed diabetes mellitus after acute pancreatitis: a systematic review and meta-analysis. Gut. 2014; 63: 818-31.

13. Higgins JPT GS. Cochrane Handbook for Systematic Reviews of Interventions Version 5.1.0. The Cochrane Collaboration, 2011 Available from http://handbookcochraneorg. 2011.

14. Higgins JP, Thompson SG, Deeks JJ, Altman DG. Measuring inconsistency in meta-analyses. BMJ (Clinical research ed). 2003; 327: 557-60.

15. Jackson D, White IR, Thompson SG. Extending DerSimonian and Laird's methodology to perform multivariate random effects meta-analyses. Statistics in medicine. 2010; 29: 1282-97.

16. Egger M, Davey Smith G, Schneider M, Minder C. Bias in meta-analysis detected by a simple, graphical test. BMJ (Clinical research ed). 1997; 315: 629-34.

17. Xu Y, Zhao G, Pu N, Nuerxiati A, Ji Y, Zhang L, et al. One Hundred Twenty-One Resected Solid Pseudopapillary Tumors of the Pancreas: An 8-Year Single-Institution Experience at Zhongshan Hospital, Shanghai, China. Pancreas. 2017; 46: 1023-8.

18. Xu MY, Shi XJ, He L, Lu F, Chen MY, Wang HG, et al. Clinicopathological characteristics and prognosis of solid pseudopapillary neoplasm of the pancreas: comparison between tumors $</=5 \mathrm{~cm}$ and larger tumors. Nan Fang Yi Ke Da Xue Xue Bao. 2016; 36: 780-4.

19. Kang CM, Choi SH, Kim SC, Lee WJ, Choi DW, Kim SW. Predicting recurrence of pancreatic solid pseudopapillary tumors after surgical resection: a multicenter analysis in Korea. Ann Surg. 2014; 260: 348-55.

20. Hwang J, Kim DY, Kim SC, Namgoong JM, Hong SM. Solid-pseudopapillary neoplasm of the pancreas in children: can we predict malignancy? J Pediatr Surg. 2014; 49: 1730-3.

21. Kim CW, Han DJ, Kim J, Kim YH, Park JB, Kim SC. Solid pseudopapillary tumor of the pancreas: can malignancy be predicted? Surgery. 2011; 149: 625-34.

22. Machado MC, Machado MA, Bacchella T, Jukemura J, Almeida JL, Cunha JE. Solid pseudopapillary neoplasm of the pancreas: distinct patterns of onset, diagnosis, and prognosis for male versus female patients. Surgery. 2008; 143: 29-34.

23. Serrano PE, Serra S, Al-Ali H, Gallinger S, Greig PD, McGilvray ID, et al. Risk factors associated with recurrence in patients with solid pseudopapillary tumors of the pancreas. Jop. 2014; 15: 561-8.

24. Irtan S, Galmiche-Rolland L, Elie C, Orbach D, Sauvanet A, Elias D, et al. Recurrence of Solid Pseudopapillary Neoplasms of the Pancreas: Results of a Nationwide Study of Risk Factors and Treatment Modalities. Pediatr Blood Cancer. 2016; 63: 1515-21.

25. Marchegiani G, Andrianello S, Massignani M, Malleo G, Maggino L, Paiella S, et al. Solid pseudopapillary tumors of the pancreas: Specific pathological features predict the likelihood of postoperative recurrence. J Surg Oncol. 2016; 114: 597-601.

26. Estrella JS, Li L, Rashid A, Wang H, Katz MH, Fleming JB, et al. Solid pseudopapillary neoplasm of the pancreas: clinicopathologic and survival analyses of 64 cases from a single institution. Am J Surg Pathol. 2014; 38: 147-57.

27. Lau J, Ioannidis JP, Terrin N, Schmid CH, Olkin I. The case of the misleading funnel plot. BMJ (Clinical research ed). 2006; 333: 597-600.

28. Lahat G, Ben Haim M, Nachmany I, Sever R, Blachar A, Nakache R, et al. Pancreatic incidentalomas: high rate of potentially malignant tumors. J Am Coll Surg. 2009; 209: 313-9.

29. Raman SP, Kawamoto S, Law JK, Blackford A, Lennon AM, Wolfgang CL, et al. Institutional experience with solid pseudopapillary neoplasms: focus on computed tomography, magnetic resonance imaging, conventional ultrasound, endoscopic ultrasound, and predictors of aggressive histology. J Comput Assist Tomogr. 2013; 37: 824-33.

30. Naar L, Spanomichou DA, Mastoraki A, Smyrniotis V, Arkadopoulos N. Solid Pseudopapillary Neoplasms of the Pancreas: A Surgical and Genetic Enigma. World journal of surgery. 2017; 41: 1871-81.

31. Wang DB, Wang QB, Chai WM, Chen KM, Deng XX. Imaging features of solid pseudopapillary tumor of the pancreas on multi-detector row computed tomography. World J Gastroenterol. 2009; 15: 829-35.

32. Morikawa T, Onogawa T, Maeda S, Takadate T, Shirasaki K, Yoshida H, et al. Solid pseudopapillary neoplasms of the pancreas: an 18-year experience at a single Japanese Institution. Surg Today. 2013; 43: 26-32.

33. Zhang $\mathrm{H}$, Wang $\mathrm{W}, \mathrm{Yu} \mathrm{S}$, Xiao $\mathrm{Y}$, Chen $\mathrm{J}$. The prognosis and clinical characteristics of advanced (malignant) solid pseudopapillary neoplasm of the pancreas. Tumour Biol. 2016; 37: 5347-53.

34. Jutric Z, Rozenfeld Y, Grendar J, Hammill CW, Cassera MA, Newell PH, et al. Analysis of 340 Patients with Solid Pseudopapillary Tumors of the Pancreas: A Closer Look at Patients with Metastatic Disease. Ann Surg Oncol. 2017; 24: 2015-22.

35. Butte JM, Brennan MF, Gonen M, Tang LH, D'Angelica MI, Fong Y, et al. Solid pseudopapillary tumors of the pancreas. Clinical features, surgical outcomes, and long-term survival in 45 consecutive patients from a single center. J Gastrointest Surg. 2011; 15: 350-7. 